\title{
Scaphoid fractures
}

\author{
Robert S Richards MD FRCSC, James H Roth MD FRCSC FACS \\ Divisions of Orthopaedic and Plastic Surgery, Department of Surgery, The University of \\ Western Ontario; and Hand and Upper Limb Centre, St Joseph's Health Centre, London, \\ Ontario
}

\begin{abstract}
RS Richards, JH Roth. Scaphoid fractures. Can J Plast Surg 1996;4(3):143-149. Scaphoid fractures are the most common carpal bone fractures and present physicians with many problems. The majority of such fractures $(90 \%)$ will unite if properly treated; however a scaphoid fracture that goes on to nonunion affects a patient's working capacity for a long period of time. This paper reviews the pathophysiology of the injury and outlines the diagnostic and treatment options available.
\end{abstract}

Key Words: Fractures, Nonunions, Scaphoid, Treatment

\section{Les fractures du scaphoïde}

RÉSUMÉ : Les fractures du scaphoïde sont les plus courantes des fractures osseuses carpiennes, et posent de nombreux problèmes aux médecins. La majorité de ce type de fractures $(90 \%)$ vont se souder si elles sont traitées de manière appropriée; cependant, une fracture du scaphoïde qui ne se consolide pas affecte la capacité d'un patient à travailler pendant une longue période de temps. Cet article passe en revue la physiopathologie de la blessure et donne un aperçu du diagnostic et des solutions thérapeutiques disponibles.

Scaphoid fractures are the most common carpal bone fractures and are second only to distal radius fractures in frequency of fractures of the hand and wrist. Scaphoid fractures are reported to occur with a frequency of 35 fractures per 250,000 population, but the true incidence may be many times higher (1). Although scaphoid fractures are most commonly seen in young males in their second to fourth decades of life, they can occur in children. While $90 \%$ of scaphoid fractures will unite if properly treated, the disability from a scaphoid fracture that goes on to nonunion affects the working capacity of patients for a prolonged period of time. Treatment of the nonunion can be difficult. Thus primary treatment of the scaphoid fracture is highly important. Successful treatment is enhanced by an understanding of both the pathophysiology of the injury as well as the diagnostic and treatment options available.

\section{ETIOLOGY}

Scaphoid fractures are usually the result of a fall onto a dorsiflexed and radially deviated wrist. Weber and Chao (2) have noted that wrist dorsiflexion of $95^{\circ}$ to $100^{\circ}$ resulted in scaphoid fractures. This degree of dorsiflexion results in a bending load applied to the distal one-half of the scaphoid. The proximal half is stabilized among the 
radius, the capitate and the palmar radiocarpal ligaments, resulting in a fracture through the scaphoid waist (2).

Russe classified fractures according to both their location and orientation (3). The location of the fracture affects the risk of nonunion with proximal pole fractures having the highest risk of nonunion. Proximal pole fractures also take the longest time to unite both acutely and after bone grafting.

The blood supply of the scaphoid has been well documented by Gelberman and Botte (4). The palmar blood supply accounts for $20 \%$ to $30 \%$ of the total blood supply, mostly in the distal pole. The dorsal blood supply accounts for the remaining $70 \%$ to $80 \%$ and enters the scaphoid through multiple foramina. The proximal pole is dependent on endosteal bloodflow, with $13 \%$ of scaphoids having no foramina proximal to the waist and $20 \%$ having only one foramina proximal to the waist. Thus, proximal pole vascularity is a concern in fractures proximal to the waist. Avascular necrosis of the proximal pole may appear on plain radiographs as proximal pole sclerosis. This is a worrisome radiographical finding but does not play a role in the development of nonunion (5). Early changes in radiodensity that reverse are commonly seen and may be related to fracture healing and revascularization. However, the presence of radiographical changes of possible avascular necrosis indicates fractures that may require prolonged immobilization to unite. Failure to recognize possible avascular necrosis and the associated need for prolonged immobilization results in inadequate length of immobilization and nonunion. Avascular necrosis plays a role in the success of bone grafting with low union rates when avascular proximal poles are bone grafted (6).

Although the vast majority of scaphoid fractures unite, reported rates of nonunion vary from $5 \%$ to $50 \%(7,8)$. Early diagnosis, bone apposition, adequate blood supply and fracture immobilization are required to obtain union (5).

Multiple risk factors for scaphoid nonunion exist. Displacement of a scaphoid fracture is the most important etiological factor in nonunion. Displacement of only $1 \mathrm{~mm}$ significantly increases the risk of nonunion if the fracture is treated nonoperatively. The nonunion rate in undisplaced scaphoid fractures treated with immobilization is only $5 \%$ (9). The risk of nonunion in displaced fractures treated nonoperatively with immobilization ranges from $46 \%$ to $92 \%$ (10). As a result open reduction and internal fixation are indicated for all displaced fractures.

A dorsal intercalary segmental instability (DISI) pattern may be present on the lateral x-ray with the lunate in a dorsiflexed position. This is associated with a scapholunate angle greater than $70^{\circ}$ and a radiolunate angle greater than $10^{\circ}$ dorsal. Weber (11) found the presence of a DISI pattern on the lateral x-ray was associated with disruption of the dorsal and volar ligaments, and increased instability, increasing the risk of nonunion.

Failure of the patient to seek medical attention is another risk factor for the development of nonunion. A delay in treatment greater than six months is associated with a high risk of nonunion. Although the position of immobilization has been felt to be a risk factor for nonunion the length of immobilization is more important than the position. Many different types and positions of immobilization ranging from long arm casting to functional bracing have been advocated with equal success (12). A greater risk factor for nonunion is inadequate length of immobilization. Immobilization should not be discontinued until union is assured. This requires either planar tomography or computed 
tomography (CT) to determine whether union has occurred (Figure 1,2). Assessment of union on plain radiographs is not reliable.

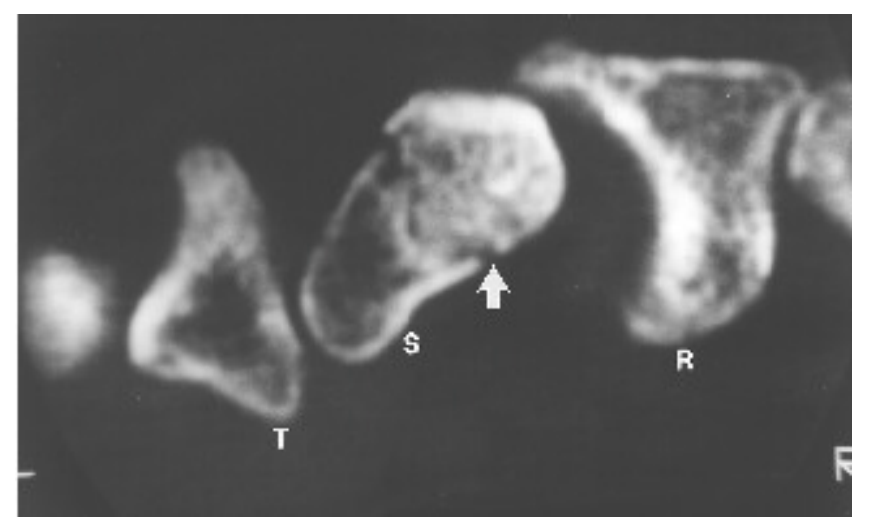

Figure 1) Long axis computed tomography scan demonstrating the radius (R), scaphoid (S), trapezium (T) and the fracture site (arrow). No trabeculations are seen to cross the fracture site

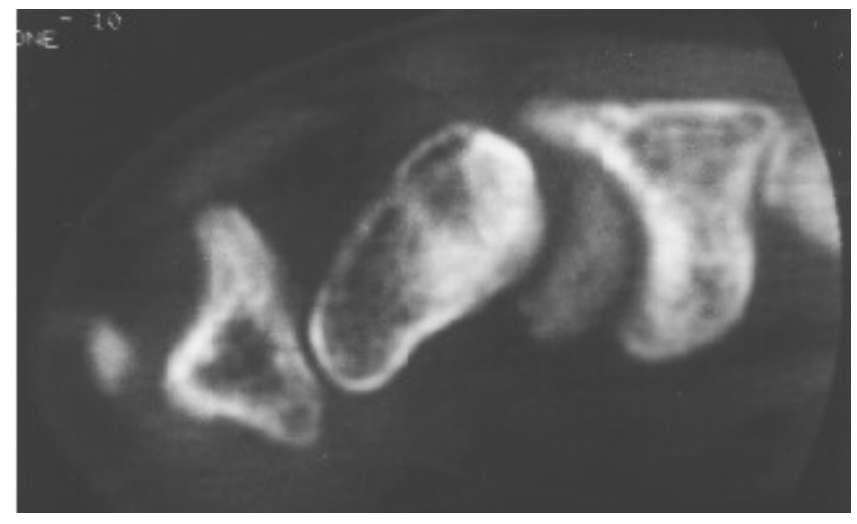

Figure 2) Repeat computed tomography scan six weeks after the initial scan shows fracture union

\section{DIAGNOSIS}

The first essential in diagnosis of a scaphoid fracture is clinical suspicion. Patients presenting with wrist pain after a fall should undergo careful examination, both clinical and radiological. Loss of the normal contour of the snuffbox is indicative of an intraarticular hemarthrosis but can be associated with either a fracture or a ligamentous injury. Although snuffbox tenderness is the classic sign associated with a scaphoid fracture, it can be equivocal. In patients with a positive history and physical examination, proper radiographs, including scaphoid views, are essential. If scaphoid views are included with standard wrist views, the vast majority of fractures are seen on the initial radiograph. The true clinical scaphoid with normal initial radiographs is rare and accounts for approximately only $3 \%$ of scaphoid fractures (13). If a strong clinical suspicion exists and the initial radiographs are inconclusive, the patient should be immobilized in a cast and repeat radiographs taken in 10 days. If these are still inconclusive, further investigation 
should consist of either a CT or a bone scan. The definitive investigation for scaphoid fractures is a CT scan which allows definite diagnosis of the fracture as well as assessment of possible displacement which would require surgery (Figure 3). If a bone scan is positive, it still needs to be followed by CT scan to delineate the fracture.

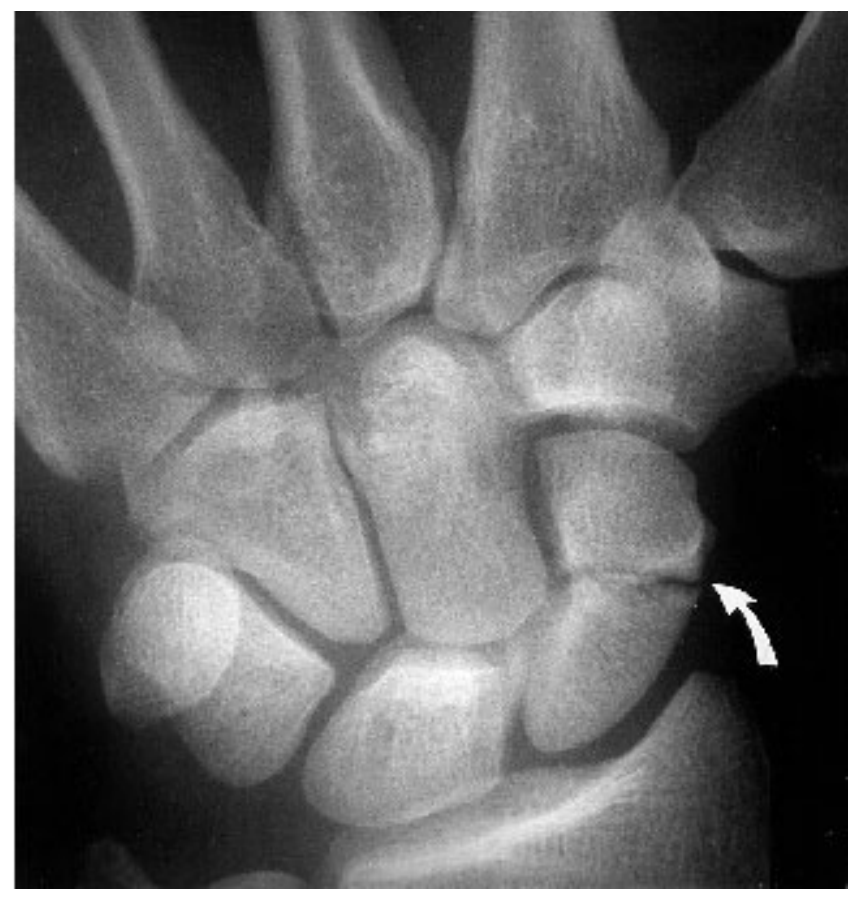

Figure 3a) Plain radiograph of an apparently undisplaced scaphoid fracture. Careful assessment of the cortical lines raises the question of possible displacement (arrow)

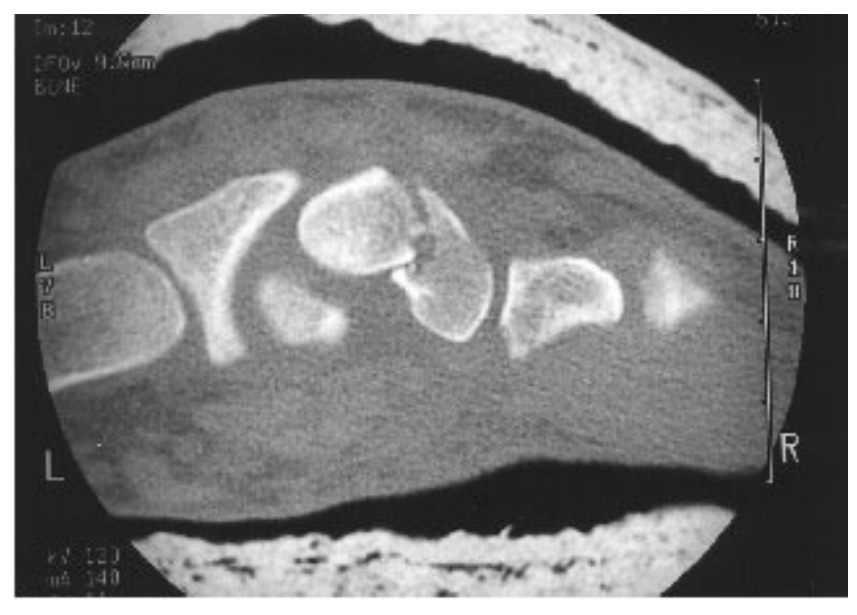

Figure 3b) Fracture displacement and apex dorsal angulation is confirmed on computed tomography scan 


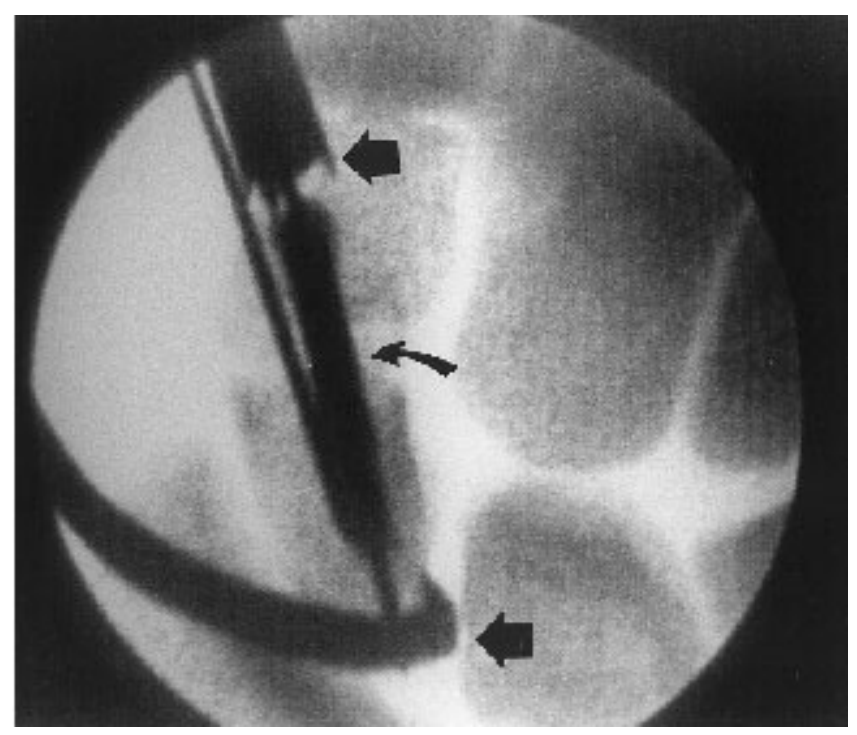

Figure 3c) Treatment consisted of arthroscopic reduction and internal fixation with a cannulated Herbert-Whipple screw. This intraoperative radiograph shows the proximal and distal aspects of the insertion jig (straight arrows) with the screw being inserted over the guide wire (curved arrow)

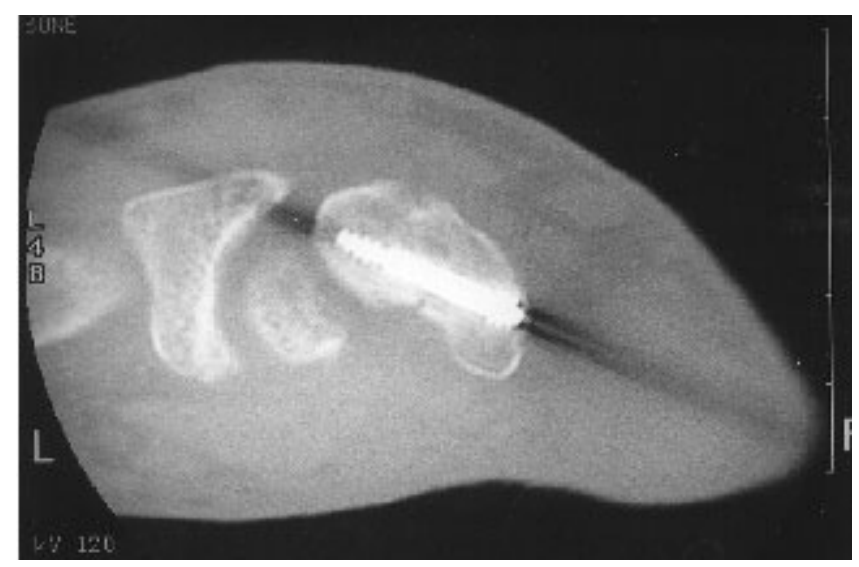

Figure 3d) Postoperative computed tomography scan confirms correction of the intrascaphoid angulation

\section{TREATMENT OF SCAPHOID FRACTURES}

\section{Nonoperative}

The majority of scaphoid fractures are undisplaced and are treated nonoperatively with cast immobilization. Although long arm casts and casts incorporating the index and middle fingers have been suggested, our preferred treatment is a short arm thumb spica with the thumb interphalangeal joint free (Figure 4 ). The wrist is placed in radial deviation as this has been shown to cause less distraction of the fragments (11). No evidence exists to prove greater efficacy for one casting position over another. Although 
above elbow casts may have a slightly shorter time to union, the final rate of union is the same for below or above elbow casts (12). The key factor in treatment of scaphoid fractures is the duration of immobilization rather than the specific position. Times to union are quoted as eight weeks for distal pole fractures, 12 weeks for waist fractures and 20 to 24 weeks for proximal pole fractures. However, in Dickinson et al's series (14), only $75 \%$ of waist fractures were healed at three months and $25 \%$ needed up to nine months to unite. Removal of the cast should not occur until union has been documented on CT or planar tomography. Fractures of the tuberosity need not be casted and should be splinted for comfort only.

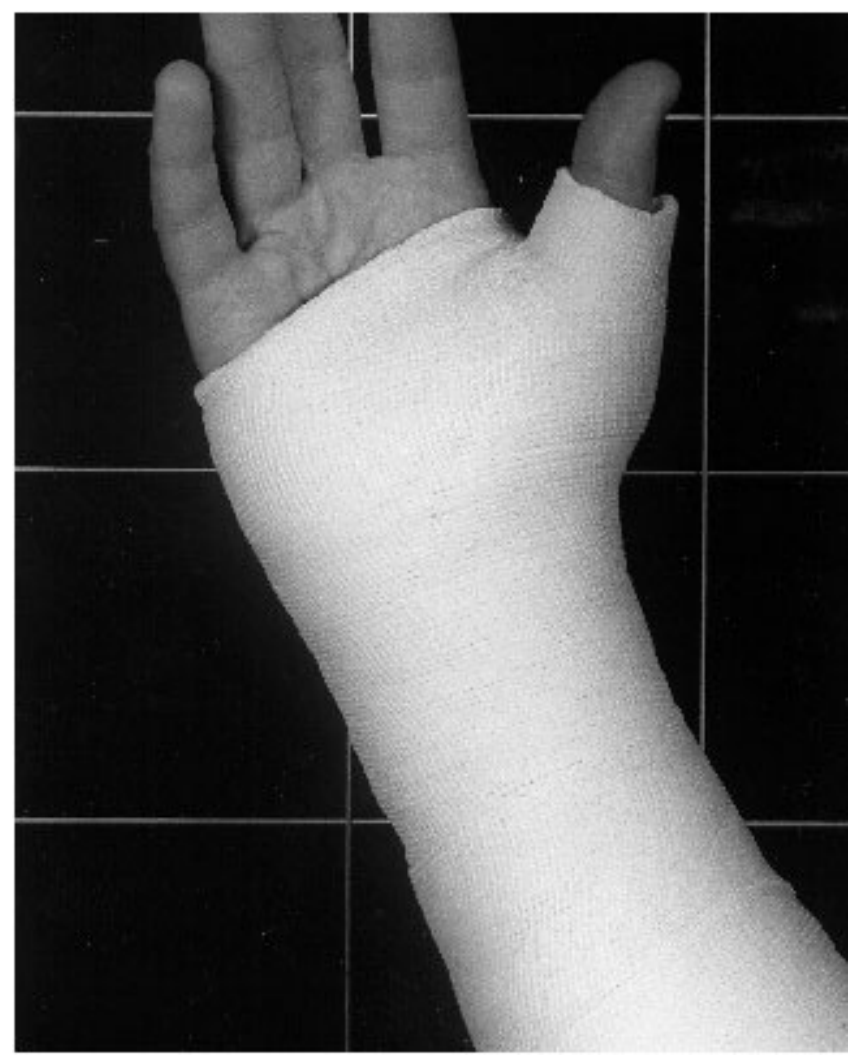

Figure 4) Position of immobilization of a scaphoid fracture. The wrist is placed in slight flexion and radial deviation. The interphalangeal joint of the thumb is left free

Initial delay in treatment does not preclude casting. If treatment is instituted within four weeks no effect on healing time or rate of union has been shown. Delay beyond six months invariably requires operative treatment (15). The difficulty lies in fractures between six weeks and six months. If no evidence of bony resorption exists, casting may result in union. If bony resorption or displacement greater than $1 \mathrm{~mm}$ exists, operative reduction and bone grafting will be needed.

\section{Open reduction and internal fixation}

Indications for operative treatment include displaced fractures with a displacement of greater than $1 \mathrm{~mm}$ (Figures $3 \mathrm{a}, \mathrm{b}$ ). As well, the presence of a DISI pattern with a scapholunate angle greater than $70^{\circ}$ indicates a ligamentous injury which 
will result in instability of the fracture fragments and an increased risk of nonunion. Other indications for open reduction and internal fixation include trans-scaphoid perilunate fracture dislocations or multiple fractures. Open reduction and internal fixation is performed through a volar approach to minimize the disturbance to the blood supply of the scaphoid. The exception to this occurs in fractures through the proximal $25 \%$ of the scaphoid in which a dorsal approach is used. Although $\mathrm{K}$-wire fixation is a valuable technique, in acute fractures the most common method of fixation used is the Herbert screw or the cannulated Herbert-Whipple screw. The surgeon must be familiar with both using the guide as well as freehand insertion of the screws to avoid complications. Complications from improper screw placement are common (Figure 5). Properly used, the Herbert screw allows early active motion without the requirement for prolonged casting.

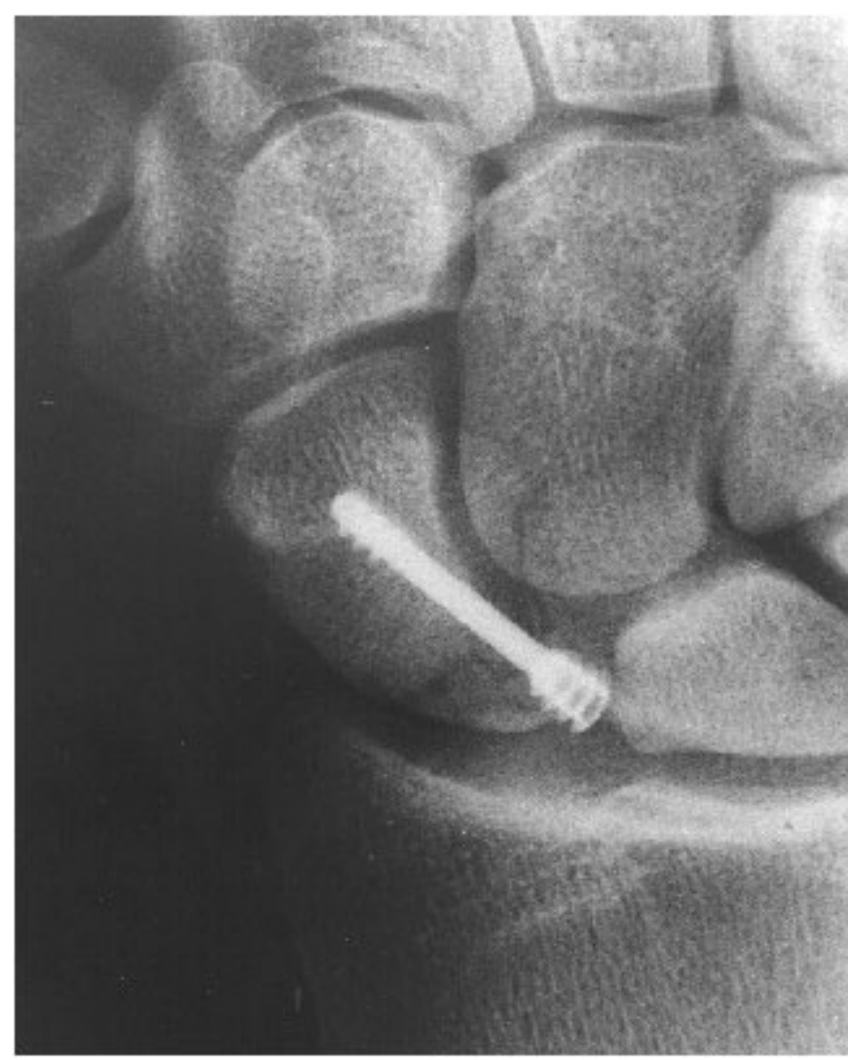

Figure 5) X-ray of a patient with ongoing pain and disability from a Herbert screw improperly inserted into a proximal pole fracture

\section{FOLLOW-UP OF SCAPHOID FRACTURES}

Nonunion of the scaphoid can be defined as a failure of bone trabeculations to cross the fracture site. The distinction between delayed union and nonunion can be difficult, especially in proximal pole fracture. Delayed union is present if no evidence of union exists at four months (5). A nonunion can be identified at six months if no radiographical evidence of union exists (5). The best method of establishing the presence 
of bony union is a long axis CT scan of the scaphoid (Figures 1,2). Planar tomography, arthrograms, magnetic resonance imaging (MRI) and plain films give far less accurate information about the presence of union. MRI has been shown to visualize a fracture site long after CT or planar tomography shows bony union. Thus, the decision regarding union of bone grafts and fractures should be made upon CT or plain tomograms. Due to the difficulty of establishing union on plain radiographs, immobilization of a scaphoid fracture should not be discontinued until CT or planar tomography shows evidence of union.

\section{NATURAL HISTORY OF SCAPHOID NONUNION}

Although the usual goal in a fracture nonunion is obtaining bony union, operative intervention must offer advantages over nonoperative management. Treatment of an established nonunion is dependent on the natural history of the nonunion. Multiple authors have shown that, in patients with a symptomatic nonunion, progressive x-ray changes and increasing osteoarthritis occur with time $(16,17)$. Not all scaphoid nonunions are symptomatic, however. Asymptomatic scaphoid nonunions are often found as incidental findings on $\mathrm{x}$-rays taken for other purposes. Patients with established nonunion and osteoarthritic changes are often asymptomatic until a second fall or injury occurs. Obtaining union of the scaphoid does not prevent the development of arthritis. Lindstrom and Nystrom's 10 year follow-up (18) showed that $10 \%$ of scaphoid fractures that united primarily developed osteoarthritis. Long term follow-up of 77 Russe bone grafts (19) showed that 46 had mild and 15 had moderate to severe radiocarpal osteoarthritis. It would appear that obtaining union of a scaphoid fracture may decrease the risk and severity of osteoarthritis but cannot with certainty prevent degenerative changes.

\section{CLASSIFICATION OF SCAPHOID NONUNION}

Scaphoid nonunions are classified according to the presence or absence of scaphoid displacement, carpal instability and the extent of degenerative arthritis (20). Type I is a simple nonunion. No displacement of the fracture fragments is seen, and no degenerative arthritis or DISI deformity is present. Type II is an unstable nonunion. Displacement of greater than $1 \mathrm{~mm}$ is present between the fragments. A DISI deformity is present on the lateral x-ray. Type III nonunions have early degenerative arthritis in the radiocarpal joint. Radioscaphoid arthritis between the distal fragment and the radius with pointing of the radial styloid is seen. Type IV nonunions have both radiocarpal and midcarpal arthritis. Type I scaphoid nonunions are uncommon. Most scaphoid nonunions without arthritis fall into the unstable type II category because displacement and carpal instability are two major predisposing factors in the development of nonunion.

\section{TREATMENT OF ESTABLISHED NONUNION}

\section{Inlay bone grafting}

In 1960 Russe advocated the use of inlay grafts from a volar approach. Green (6) modified the Russe bone graft operation to use two corticocancellous struts placed with the cortical surfaces facing outward. No internal fixation is needed with the modified 
Russe approach. Correction of an intrascaphoid angular deformity or 'humpback' is not possible with the modified Russe technique. Inlay bone grafts are therefore indicated in stable nonunions only. The time to union after Russe grafting is prolonged, with an average of four to six months of cast immobilization. Long term results of Russe grafts show union rates of $86 \%$ (6) to $93 \%$ (19).

\section{Wedge interposition grafting}

Commonly, the scaphoid fragments along the volar aspect at the time of injury. With progressive resorption at the fracture site an apex dorsal angulation or humpback deformity occurs (Figure 6). CT analysis (21) of scaphoid nonunions shows a loss of approximately $10 \%$ of scaphoid volume. Consistently more volar and ulnar bone is lost than dorsal, giving a wedge or trapezoidal shaped defect.

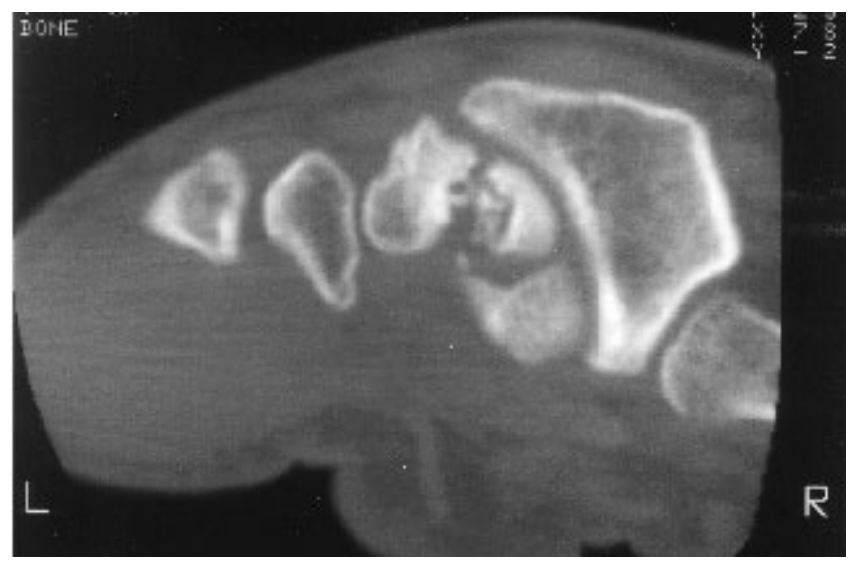

Figure 6) "Humpback" deformity of a scaphoid nonunion

The compressive forces across the wrist result in increased apex dorsal and radial angulation. Secondary intercalary instability results in the appearance of a DISI pattern on the lateral $\mathrm{x}$-ray. Incomplete correction of the deformity with subsequent malunion $(22,23)$ has been shown to result in decreased motion and increased osteoarthritis compared with scaphoids united in anatomical alignment. At $15^{\circ}$ of scaphoid angulation, all radiocarpal extension is lost and wrist extension occurs through the midcarpal joint.

Since 1984, Fernandez (24) has suggested interpositional bone grafting of the scaphoid. Although a wedge-shaped interposition bone graft corrects the humpback deformity and the DISI deformity, the wedge shape is not as inherently stable as Russe's inlay grafts and may extrude. Thus, internal fixation is necessary. K-wires, A-O screws, Herbert screws and cannulated Herbert-Whipple screws have been used (24-26). No advantage of one method over another in terms of fusion rates can be demonstrated as all have fusion rates from $82 \%$ to $97 \%$ (24-26).

Postoperatively, Herbert advocates early mobilization if his compression screw is used. However, our practice is to immobilize the interposition bone grafts for six to eight weeks followed by protective splinting until radiographical evidence of union occurs. If $\mathrm{K}$-wires are used, they remain in situ for 12 weeks or longer until union occurs.

Repeat bone grafting after a failed primary bone graft is indicated in those patients who remain symptomatic and have minimal degenerative changes. Our 
preference after a failed Russe graft is to perform interpositional wedge grafting due to the amount of sclerotic bone that needs to be resected. Union rates for a secondary bone graft average $60 \%$ compared with $70 \%$ to $90 \%$ for primary bone grafting (27).

\section{Electromagnetic stimulation}

Electromagnetic stimulation has been used for treatment of scaphoid fractures in the past decade $(28,29)$ but its effectiveness remains controversial. The advantages of external pulsed electromagnetic fields (PEMF) techniques include noninvasiveness and easy application in the clinical setting. Suggested uses of PEMF have included salvage of failed bone grafting and proximal pole nonunions, as well as an alternative to bone grafting in undisplaced scaphoid nonunions. The value of PEMF remains to be proven.

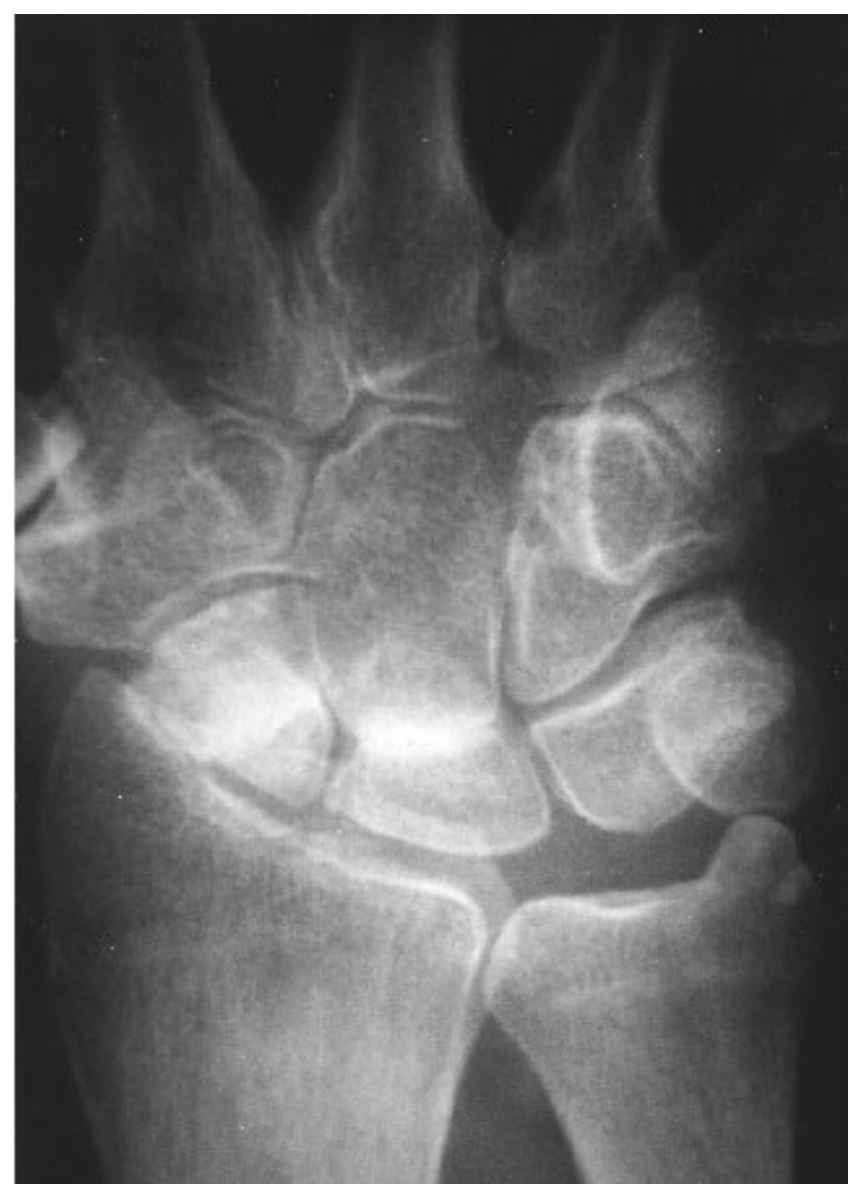

Figure 7) Posteroanterior radiograph shows scaphoid nonunion advanced collapse arthritis with radiocarpal degenerative changes between the distal fragment of the scaphoid and the radius. As well midcarpal changes among the scaphoid, capitate and lunate are seen. Radiolunate articulation and articulation between the proximal pole of the scaphoid and the radius are spared. At this point treatment would consist of limited or pancarpal wrist fusion not bone grafting 
The success rate in proximal pole nonunions is $50 \%$ to $66 \%(30)$. The average length of time required for union to occur is 4.3 months (30) but treatment may be required for six to nine months. Cast immobilization is required during treatment and patients may not tolerate prolonged immobilization. Currently bone grafting remains the gold standard for treatment of scaphoid nonunion. The use of PEMF is limited and its true indications remain to be defined.

\section{Treatment of nonunion with osteoarthritis}

If bony union is not achieved by surgery or the patient does not seek treatment, a consistent pattern of arthritis develops. Although similar to Watson's scapholunate advanced collapse pattern arthritis (31), it may be termed scaphoid nonunion advanced collapse arthritis (Figure 7). Symptoms may not occur until after a second injury. In the presence of severe osteoarthritic changes, bone grafting of the scaphoid nonunion is no longer indicated.

The first management of the painful wrist with degenerative changes is nonoperative management. This is especially true if symptoms arise after a second acute injury. Nonsteroidal anti-inflammatory medication and splinting may alleviate the patient's discomfort and avoid the need for further intervention. If symptoms persist, operative treatment is indicated. Treatment at this stage is either limited or pancarpal wrist fusion. Limited carpal fusion consists of scaphoid excision with limited wrist fusion of the proximal and distal carpal rows. The capitate, lunate, hamate and triquetrum are fused. Currently, a fascial anchovy is used or no replacement of the scaphoid is performed. The results of this procedure are mixed. Motion is preserved but residual pain may be present in $30 \%$ of patients. Reported range of motion averages $50 \%$ of the contralateral wrist. A disadvantage of limited wrist fusion is a prolonged recovery time. Final range of motion is not achieved for 18 to 24 months. Pancarpal arthrodesis remains the only salvage procedure that provides a predictable pain-free stable wrist without concern for long term durability. If the patient wishes a definitive operation for degenerative wrist arthritis, pancarpal rather than limited wrist fusion should be performed. Although patients may express concern about the loss of the flexion extension arc, wrist motion is often severely limited in these patients preoperatively and pancarpal fusion results in little additional deficit. Activity of daily living studies have shown that all activities may be performed with less than $5 \%$ of normal wrist arc of motion (32). Placing the patient in a cast preoperatively with the wrist in $10^{\circ}$ extension and $10^{\circ}$ ulnar deviation simulates the fusion and allows the patient to assess the functional effect of the wrist fusion. Excellent patient satisfaction and excellent pain relief have been reported (33). The recovery period is also shorter than for limited wrist fusion, with most patients returning to work or normal activity in a few months.

Currently, pancarpal fusion is our choice for salvage of the osteoarthritic wrist secondary to scaphoid nonunion.

\section{SUMMARY}

Scaphoid fractures are a common but a difficult problem. A clear approach to diagnosis and treatment is needed. CT scans are the best method of diagnosis and follow-up. Early treatment and careful follow-up before cast removal will result in union in the majority of 
patients. If a nonunion does occur, then bone grafting remains the gold standard treatment. Fernandez's interposition bone graft with correction of the carpal instability is the procedure of choice for the majority of scaphoid nonunions. Successful treatment of the nonunion does not guarantee a long term pain-free wrist. The definitive salvage procedure for wrists with degenerative arthritis associated with scaphoid nonunion remains a pancarpal fusion, but limited intercarpal fusions may be used to maintain motion.

\section{REFERENCES}

1. Barton NJ. Twenty questions about scaphoid fractures. J Hand Surg [Br] 1992;17:289310 .

2. Weber ER, Chao EY. An experimental approach to the mechanism of scaphoid waist fracture. J Hand Surg 1978;3:142-8.

3. Szabo RM, Manske D. Displaced fractures of the scaphoid. Clin Orthop 1988;230:308.

4. Gelberman RH, Botte MJ. Vascularity of the carpus. In: Lichtman DM, ed. The Wrist and Its Disorders. Philadelphia: WB Saunders and Company, 1988:27-40.

5. Roth JH, Urbaniak JR. Non-union of the scaphoid. Transplant Implant Today 1988;5:44-56.

6. Green DP. The effect of avascular necrosis on Russe bone grafting for scaphoid nonunion. J Hand Surg 1985;10:597-605

7. Leslie IJ, Dickson RA. The fractured carpal scaphoid: Natural history and factors influencing outcome. J Bone Joint Surg 1981;63:225-30.

8. Cooney WP, Dobyns JH, Linscheid RL. Fractures of the scaphoid:

A rational approach to management. Clin Orthop 1980;149:90-7.

9. Osterman AL, Mikulics M. Scaphoid nonunion. Hand Clin 1988;14:437-55.

10. Szabo RM, Manske D. Displaced fractures of the scaphoid. Clin Orthop 1988;230:308.

11. Weber ER. Biomechanical implications of scaphoid waist fractures. Clin Orthop 1980;149:83-9.

12. Osterman AL. Closed treatment of scaphoid fractures. Scaphoid Fractures and Complications. Rosemont: American Academy of Orthopedic Surgeons [monograph series], 1994;21-25.

13. Young MRA, Lowry JH, McLeod NW, et al. Clinical carpal scaphoid injuries. BMJ 1988;296:825-6.

14. Dickinson JC, Shannon JG. Fractures of the carpal scaphoid in the Canadian army: Review and commentary. Surg Gynecol Obst 1944;79:225-39.

15. Langhoff O, Anderson JL. Consequences of late immobilization of scaphoid fractures. J Hand Surg 1988;13:77-9.

16. Mack GR, Bosse MJ, Gelberman RH, et al. The natural history of scaphoid nonunion. J Bone Joint Surg 1984;66:504-9.

17. Lindstrom G, Nystrom A. Natural history of scaphoid nonunion with special reference to asymptomatic cases. J Hand Surg 1992;17:697-700.

18. Lindstrom G, Nystrom A. Incidence of post-traumatic arthritis after primary healing of scaphoid fractures: A clinical and radiological study. J Hand Surg 1990;15:11-3. 
19. Hooning Van Duyvenbode JFF, Keijser LCM, Hauet EJ, et al. Pseudarthrosis of the scaphoid treated by the Matti-Russe operation.

J Bone Joint Surg 1991;73:603-6.

20. Mack GR, Lichtman DM. Scaphoid nonunion. In: Lichtman DM, ed. The Wrist and

Its Disorders. Philadelphia: WB Saunders and Company, 1988:293-328.

21. Belsole RJ, Hilbelink DR, Llewellyn JA, et al. Computed analyses of the pathomechanics of scaphoid waist nonunions. J Hand Surg 1991;16:899-906.

22. Amadio PC, Berquist TH, Smith DK. Scaphoid malunion. J Hand Surg 1989;14:67987.

23. Burgess RC. The effect of a simulated scaphoid malunion on wrist motion. J Hand Surg 1987;12:774-6.

24. Fernandez DL. A technique for anterior wedge-shaped grafts for scaphoid nonunions with carpal instability. J Hand Surg 1984;9:733-7.

25. Fernandez DL. Anterior bone grafting and conventional lag screw fixation to treat scaphoid nonunions. J Hand Surg 1990;15:140-7.

26. Herbert TJ, Fisher WE: Management of the fractured scaphoid using a new bone screw. J Bone Joint Surg 1984;66:114-23.

27. Carrozzella JC, Stern PJ, Murdock PA. The fate of failed bone graft surgery for scaphoid nonunions. J Hand Surg 1989;14:800-6.

28. Bora FW, Osterman AL, Brighton CT. The electrical treatment of scaphoid nonunion. Clin Orthop 1981;161:30-8.

29. Adams BD, Frykman GK, Taleisnik J. Treatment of scaphoid nonunion with casting and pulsed electromagnetic fields: a study continuation.

J Hand Surg 1992;17:910-3.

30. Osterman AL, Bora FW. Electrical stimulation applied to bone and nerve injuries in the upper extremity. Orthop Clin North Am 1986;17:353-64.

31. Watson HK, Ballet FL. The SLAC wrist: Scapholunate advanced collapse pattern of degenerative arthritis. J Hand Surg 1984;9:358-65.

32. Nelson DL, Mitchell MA, Manske PR, et al. Functional wrist range of motion.

Phoenix, American Society for Surgery of the Hand Annual Meeting, November 11-14, 1992.

33. Richards RS, Roth JH. Simultaneous proximal row carpectomy and radius to distal

carpal row arthrodesis. J Hand Surg 1994;17:728-32. 